\section{Probiotic Administration Increases Mandibular Bone Mineral Density on Rats Exposed to Cigarette Smoke Inhalation}

Yara Loyanne de Almeida Silva Levi ${ }^{1} \mathbb{D}$, Raquel Narciso Picchi ${ }^{1} \mathbb{D}$, Evelyn

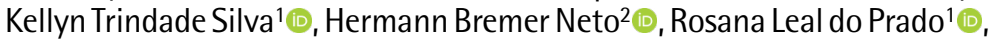

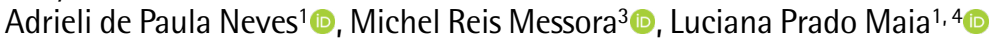

\begin{abstract}
Smoking is one of the main risk factor for periodontal disease, increasing its prevalence and severity. Probiotics emerged as an alternative for the prevention and treatment of many diseases, since it can modulate the host immune response and modify the modify the microbiome. Therefore, the aim of the present study is to evaluate the effects of probiotic administration on the periodontal tissues in rats exposed to cigarette smoke inhalation (CSI). Forty rats were allocated into the following groups $(n=10)$ : group C (control, without CSI and probiotic); group PROB (control+probiotic); group CSI (CSI) and group $\mathrm{CSI}+\mathrm{PROB}$ (CSI+probiotic). Groups PROB and $\mathrm{CSI}+\mathrm{PROB}$ received $2 \mathrm{~g}$ of an association of probiotic microorganisms incorporated into the feed during 6 months. Groups CSI and CSI+PROB were exposed to CSI for $60 \mathrm{~min}$ daily. After six months all the animals were euthanized and the hemi-mandibles were collected and processed for microcomputed tomography analyses. Regarding the body weight of the animals, feed consumption was similar among the groups, however, after the second month groups $\mathrm{C}$ and PROB showed higher body weight gain when compared to groups CSI and CSI+PROB $(p<0.05)$. Group CSI presented reduced bone mineral density (BMD), whereas group PROB showed the highest values $(p=0.01)$. It can be concluded that administration of probiotics promoted an increase in BMD and, consequently, a protective effect on the mandibular bone structures in rats exposed to inhalation of cigarette smoke.
\end{abstract}

'Graduate Program in Dentistry, UNOESTE - Universidade do Oeste Paulista, Presidente Prudente, SP, Brazil

${ }^{2}$ Department of Functional Sciences, UNOESTE - Universidade do Oeste Paulista, Presidente Prudente, SP, Brazil ${ }^{3}$ Departament of Oral and Maxillofacial Surgery and Periodontology, School of Dentistry of Ribeirão Preto, USP - Universidade de São Paulo, Ribeirão Preto, SP, Brazil ${ }^{4}$ Graduate Program in Rehabilitation Sciences, UNOPAR - Universidade Norte do Paraná, Londrina, PR, Brazil

Correspondence: Luciana Prado Maia, Rua José Bongiovani, 700, Bloco B, 19050-680 Presidente Prudente, SP, Brasil. Tel: +55-18-3229-1052. e-mail: lucianapmaia@gmail.com

Key Words: bone density, periodontitis, probiotics, smoking.

\section{Introduction}

Periodontal disease severity in smokers reflects the activity of tobacco components over the host. Studies showed that cigarette smoke inhalation leads to a decrease in mineralized bone tissue volume in the furcation area and reduces bone repair rate (1), whereas the subcutaneous injection of nicotine results in greater bone loss in the furcation are of mandibular molars (2). Clinical trials showed that smoking produces an adverse effect on clinical periodontal parameters and alveolar bone height and density, acting as a potential risk factor for alveolar bone loss, even at an early age with low tobacco consumption (3).

It is well known that periodontal disease causes alveolar bone resorption, while osteoporosis leads to a decrease on bone mass. Thereby, it is possible to establish a relationship between both diseases, since the systemic bone loss that occurs in osteoporosis decrease bone mineral density (BMD), favoring alveolar bone resorption by periodontal disease (4). The regional increase of proinflammatory cytokines caused by periodontal disease accelerates the systemic bone resorption as they induce osteoclastic activity and act as a main determinant of osteoporosis (5). Due to all these changes, smokers present a low BMD (6) and the current literature highlight the importance to consider these individuals with a high risk level for osteoporosis development and bone fractures.

Probiotics emerged as an alternative for the prevention and treatment of many diseases, since it can modulate the host immune response and modify the modify the microbiome. Bifidobacterium and Lactobacillus are the probiotic microorganisms most studied, but the yeast Saccharomyces cerevisiae and some species of $\mathrm{E}$. coli and Bacillus also have been investigated. Studies have shown probiotic effectiveness in favoring the nonspecific phagocytosis of macrophages, suggesting a systemic activity by secreting mediators that would stimulate the autoimmune system, also acting in the intestinal microbiota balance and leading to an increase in the resistance against infections (7). Since probiotics can modulate the host immune response by reducing the pro-inflammatory cytokines production and increasing the anti-inflammatory cytokines production (8), it is inferred that they can reduce bone resorption. Probiotics may decrease the amount of macrophages and the expression of tumor necrosis factor alpha (TNF- $\alpha$ ), interleukine (IL)- $1 \beta$ and receptor activator of nuclear kappa-B ligand (RANKL), as well as increase the production of osteoprotegerin (OPG) (9), and reduce the amount of osteoclasts in the periodontal tissues of 
mechanically loaded teeth (8). The ability of probiotics to increase bone mass in chickens and prevent alveolar bone loss in rats by increasing bone density was also demonstrated (10).

Additionally, considering probiotics capacity of reducing the risks of chronic disease development, studies are proving their effects on periodontal disease prevention, showing that this therapy decreases periodontal tissues destruction (11). It also improves clinical parameters, such as probing pocket depth and gingival bleeding on probing (12), besides modulating immune-inflammatory and microbiological parameters (11). Moreover, clinical trials reported that probiotic therapy enhances the effects of scaling and root planning in the treatment of periodontal diseases (13).

Considering that the two main strategies for the treatment of periodontal diseases are the elimination of specific pathogens and suppression of destructive host response, the use of probiotics represents a promising method to achieve these goals (14). Although there are a variety of drugs used to treat osteoporosis, it is necessary to consider the variable efficacy and the various side effects caused by the available medication. Thus, preventive strategies using a non-pharmacological approach, such as the addition of dietary supplements to diet, are of considerable interest (15). However, the use of this therapy is still an emerging field, and further studies are essential to establish dosage, treatment duration and route of administration (16), besides determining the real clinical significance of this therapy. In this context, the hypothesis of this study is that the administration of probiotic can promote a protective effect to the alveolar bone in animals submitted to the inhalation of the cigarette smoke. Thus, well-controlled studies and histological findings may be of great value to structure the future pillars for this therapy. The aim of the study was to evaluate the microtomographic effects of probiotic administration on periodontal tissues of rats exposed to cigarette smoke inhalation (CSI).

\section{Material and Methods}

\section{Experimental Design}

This study was performed after review and approval by the Ethics Committee on Animal Use of UNOESTE (protocol number 2600). Authors followed the ARRIVE (Animal Research: Reporting of in vivo Experiments) guidelines.

Forty male Wistar rats (Rattus norvegicus albinus) with a body mass ranging from 45 to $50 \mathrm{~g}$. The rats were kept in individual cages under the same standard conditions of illuminations (light/dark cycle of 12/12 h), controlled temperature of $22 \pm 1{ }^{\circ} \mathrm{C}$, and food and water ad libitum during all the experimental period. The experiment lasts 6 months, being 5 days of adaptation to the management and feeding with basal diet constituted of balanced commercial feed (Supralab Especial, Alisul Ind. Alimentos Ltda., São Leopoldo, RS, Brazil) and 6 months of treatment. The animals were allocated into the following groups $(n=10)$ : group $C$ (control, without $\mathrm{CSI}$ and probiotic) rats with no CSI and no PROB administration; group PROB (control+probiotic); group CSI (CSI) and group CSI+PROB (CSI+probiotic).

\section{Probiotic Administration}

Groups PROB and $\mathrm{CSI}+\mathrm{PROB}$ received $2 \mathrm{~g}$ of and association of probiotic microorganisms (Lactobacilus acidophilus - $1 \times 10^{9}$ Colony-forming unit for each kilogram of the product - CFU $/ \mathrm{kg}$; Enterococcus faecium

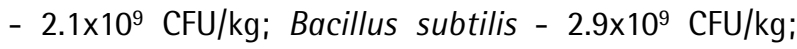
and Bifidobacterium bifidum $2 \times 10^{9} \mathrm{CFU} / \mathrm{kg}$ ) (Biomart, Martinópolis, SP, Brazil) incorporated into each $1 \mathrm{~kg}$ of feed, during 6 months. The feed was kept in a vacuum container e under refrigeration. Probiotic concentration was determined according to fabricant recommendations.

\section{Cigarette Smoke Inhalation (CSI) Protocol}

For the CSI protocol two hermetically sealed chambers were used; both with $100 \mathrm{~cm}$ in length, $40 \mathrm{~cm}$ in width and $40 \mathrm{~cm}$ in height, similar from Camargo et al. (17) and adapted from Cendon et al. (18). One chamber was used for groups $\mathrm{CSI}$ and $\mathrm{CSI}+\mathrm{PROB}$, with cigarette smoke inhalation, whereas the other one was used for groups $\mathrm{C}$ and $\mathrm{PROB}$, with inhalation of compressed air from a radial compressor (Model CRC - 221015 SS, Asten \& CIA Ltda., Brazil). Commercially available cigarettes were used (MILL, Veneto S.A., Paraguay), composed of tobacco, sugars, cigarette paper, vegetable extracts and flavoring agents, which produced at each burn $10 \mathrm{mg}$ of tar, $0.9 \mathrm{mg}$ of nicotine and $10 \mathrm{mg}$ of carbon monoxide (CO), as reported on the product packaging. The cigarette smoke chamber was divided into two compartments, one for the placement of lit cigarettes and another for the accommodation of a cage with six animals.

In the first five days, groups CSI and CSI+PROB were exposed to CSI during $10 \mathrm{~min}$, once a day, with a mean concentration of $350 \mathrm{ppm}$ (parts per million) of $\mathrm{CO}$, measured by a specific gas detector (ToxiPro ${ }^{\circledR}$, Biosystems, Michigan City, IN, USA). After this adaptation period, groups CSI and CSI+PROB were exposed to CSI for 60 min daily, divided into $30 \mathrm{~min}$ in the morning and $30 \mathrm{~min}$ in the afternoon, five days a week, with a mean concentration of $350 \mathrm{ppm}$ de $\mathrm{CO}$, for a total period of 6 months (17).

\section{Feed Intake and Body Weight Gain}

To evaluate if the intake of feed incorporated with the probiotic was similar to the intake of the basal feed, the feed consumed was weighted weekly and the monthly average intake was used for analysis. To evaluate the animals body 
conditions, they were weighted weekly and data were expressed as monthly body weight gain in relation to the initial body weight.

\section{Euthanasia and Collection of Samples}

Animals were anesthetized with an intraperitoneal injection of Tiopental (Thiopentax; Cristália Produtos Químicos Farmacêuticos Ltda., Paulínia, SP, Brazil) $(30 \mathrm{mg} / \mathrm{kg}$ body weight). Immediately after clinical death of the animals, the hemi-mandibles were resected, divided and processed in $10 \%$ formalin for $48 \mathrm{~h}$. Right hemi-mandibles were processed for histomorphometric analysis and left hemi-mandibles were processed for microtomographic analysis.

\section{Microcomputed Tomography (Micro-CT) Analysis}

Non-demineralized specimens were scanned by a cone-bean micro-CT system (Skyscan 1172, Bruker, Kontich, Belgium). The $x$-ray generator was operated at an accelerated potential of $60 \mathrm{kV}$ with a beam current of 165 $\mu \mathrm{A}$ and an exposure time of $650 \mathrm{~ms}$ per projection. Images were produced with a voxel size of $8 \times 8 \times 8 \mu \mathrm{m}$.

For volumetric measurements, a volume of interest (VOIprismatic section) was outlined from the apexes of all roots
Total Porosity ( $\mathrm{Po}(\mathrm{TOT})$ ): percentage of porosities present in the bone tissue within the VOI; iii) Trabecular Number (Tb.n): number $(\mathrm{mm})$ of bone trabeculae present within the VOI; iv) Trabecular Separation (Tb.SP): total of spaces $(\mathrm{mm})$ present among bone trabeculae within the $\mathrm{VOI} ; \mathrm{v}$ ) Bone Mineral Density (BMD): proportion (\%) of mineralized tissue present within the VOI.
Rendered reconstructions of the microtomographic sections were also obtained for all groups using an adequate software (Versão 3.1.0, Bruker, Kontich).

\section{Statistical Analysis}

Normality of errors and homoscedasticity of variances of the data were verified by the tests of Shapiro-Wilk and Bartlett, respectively. The significance level was set at 5\%.

The significance of differences among groups for feed intake was assessed by the Kruskal-Wallis test. The significance of differences among groups for body weight range was determined by analysis of variance for repeated measures (ANOVArm), followed by posthoc Tukey test. The significance of differences among groups for microtomographic (BV/TV, Po(TOT), Tb.n, Tb.SP and $\mathrm{BMD}$ ) analyses were assessed by analysis of variance (ANOVA followed by post-hoc Tukey test. The Box-cox transformation was applied to normalize data related to the variable BMD $(l=-0.004)$. The statistical software $R$ was used for these analyses (19).

\section{Results}

\section{Feed Intake and Body Weight Gain}

No significant differences were observed among groups C, PROB, CSI and CSI+PROB in terms of feed intake in anyone of the experimental periods (Fig. 1A).

In the intragroup comparisons of the body weight gain, in all groups there was a significant increase between the baseline and 6 months $(p<0.05)$. In the intergroup analyses at 1 and 2 months, no significant differences were observed among groups. At 3 months, CSI+PROB showed a significantly smaller body weight gain then group PROB $(p<0.05)$. At 4 and 6 months, PROB showed the greatest body weight gain, followed by group $C$, with groups $C S I$ and $\mathrm{CSI}+\mathrm{PROB}$ showing the lowest values $(\mathrm{p}<0.05)$ (Fig. 1B).
A

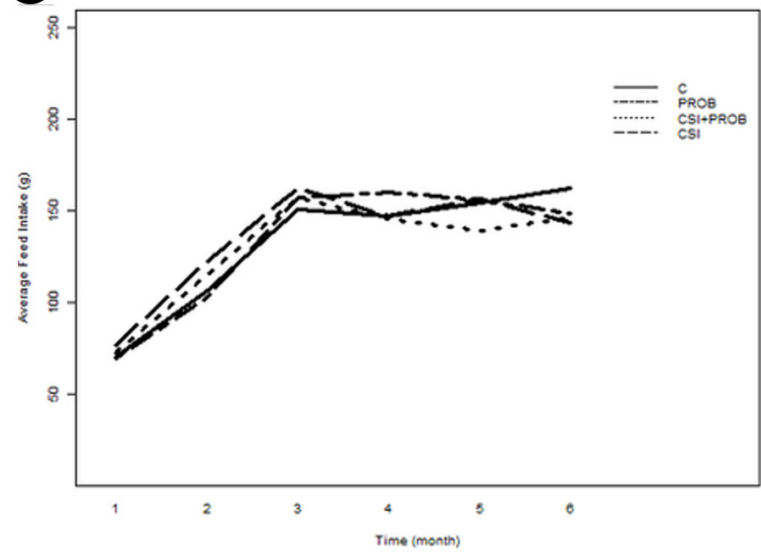

B

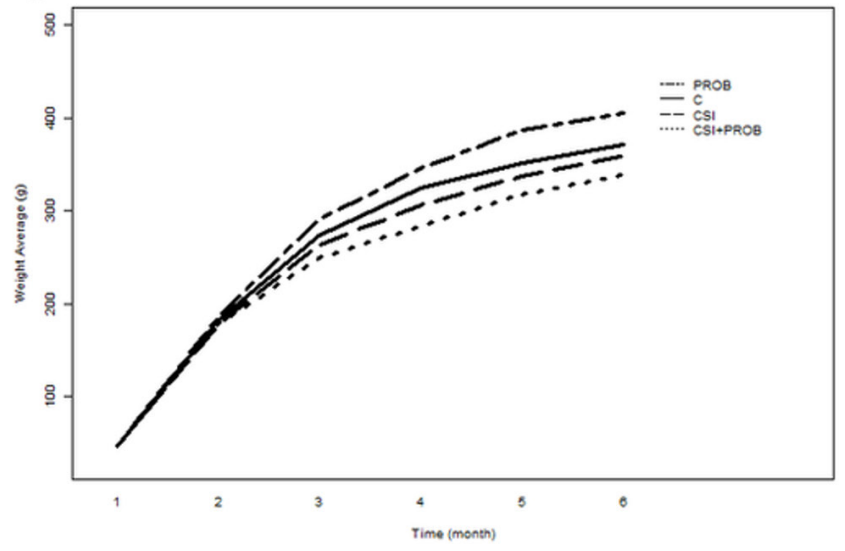

Figure 1. Mean of feed intake (A) and body weight (B) on groups C, PROB, CSI and CSI+PROB 


\section{Micro-CT Analysis}

Group CSI presented reduced values of BV, followed in an ascending order by groups $\mathrm{CSI}+\mathrm{PROB}$, $\mathrm{C}$ and $\mathrm{PROB}$, with no significant difference among the groups ( $p=0.15$ ) (Fig. 2A). Considering the bone microarchitecture in the furcation area, group CSI showed the greatest value of Po(TOT) $(p=0.11)$ (Fig. $2 B)$, Tb.n ( $p=0.83$ ) (Fig. $2 C)$ and Tb.SP $(p=0.10)$ (Fig. 2D). Regarding BMD, group CSI presented a decrease in BMD, whereas group PROB presented the greatest value among all groups ( $p=0.01$ ) (Fig. $2 E)$.

Three-dimensional rendered reconstructions of the microtomographic sections of all groups can be observed in Figure 3.

A

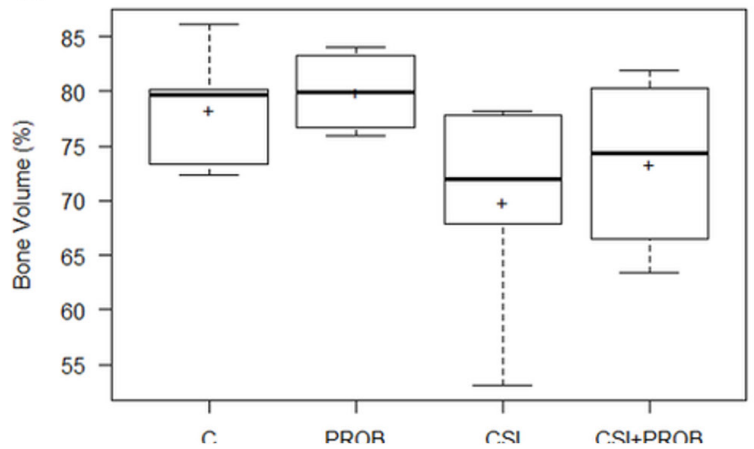

C
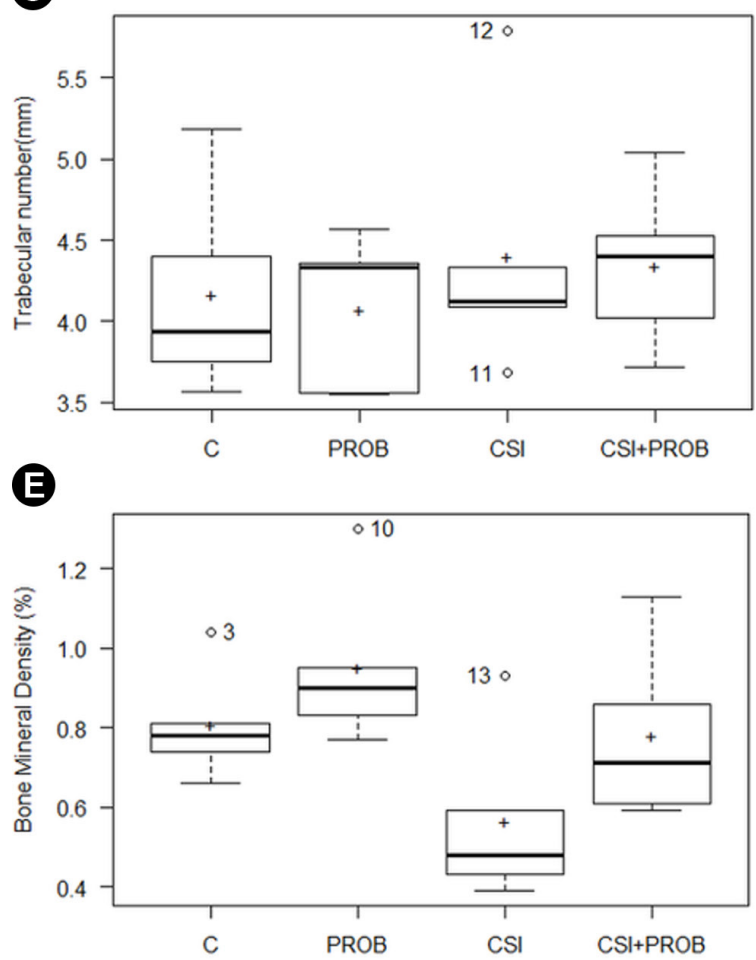

\section{Discussion}

The findings of the present study showed that rats exposed to the inhalation of cigarette smoke did not develop periodontal disease but present reduced weight and BMD. On the other hand, the administration of probiotics promoted increase in weight and BMD, improving the mandibular bone microarchitecture of the animals. A clinical study measured the effective nicotine absorption rate triggered by cigarette smoking in smokers by analyzing metabolites excreted in the urine after $24 h$, and the findings showed that individuals who smoked on average 17.9 cigarettes per day containing $11.0 \mathrm{mg}$ of tar and 1.05 $\mathrm{mg}$ of nicotine showed nicotine uptake of $24.4 \mathrm{mg}$ per day. In addition, the results of this study showed that nicotine

B

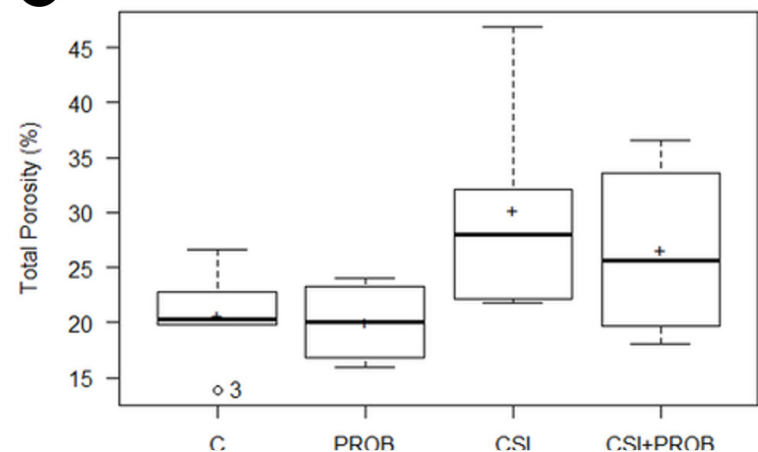

D

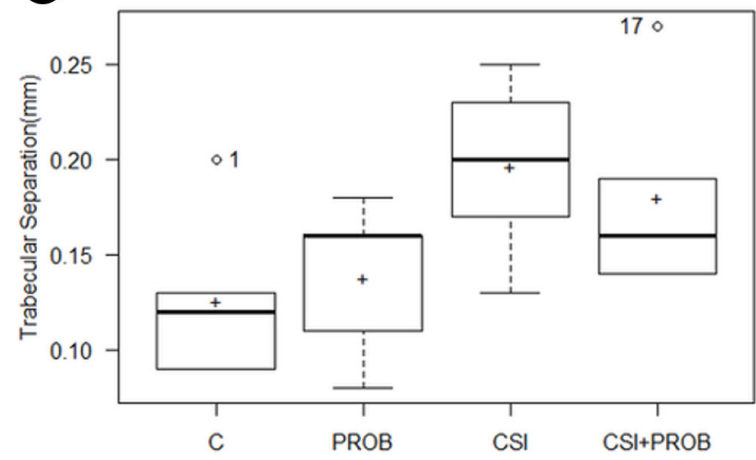

Figure 2. Means and interquartiles ranges of Bone Volume (A), Trabecular Number (B), Trabecular Separation (C), Total Porosity (D) and Bone Mineral Density (E) on groups C, PROB, CSI and CSI+PROB. Different letters indicate significant differences among groups (ANOVA, Tukey Test, p<0.05) 
metabolism is independent of the route of administration used, since it can be inhaled or injected (20). Another study evaluated the smoking characteristics of cigarette smokers in Brazil, China, Mexico and Poland, showed that the concentration of cotinine increases linearly with smoked cigarettes up to 20 per day (21). Thus, we can extrapolate the results of the present study and infer that the decrease in BMD observed in animals exposed to CSI can occur with
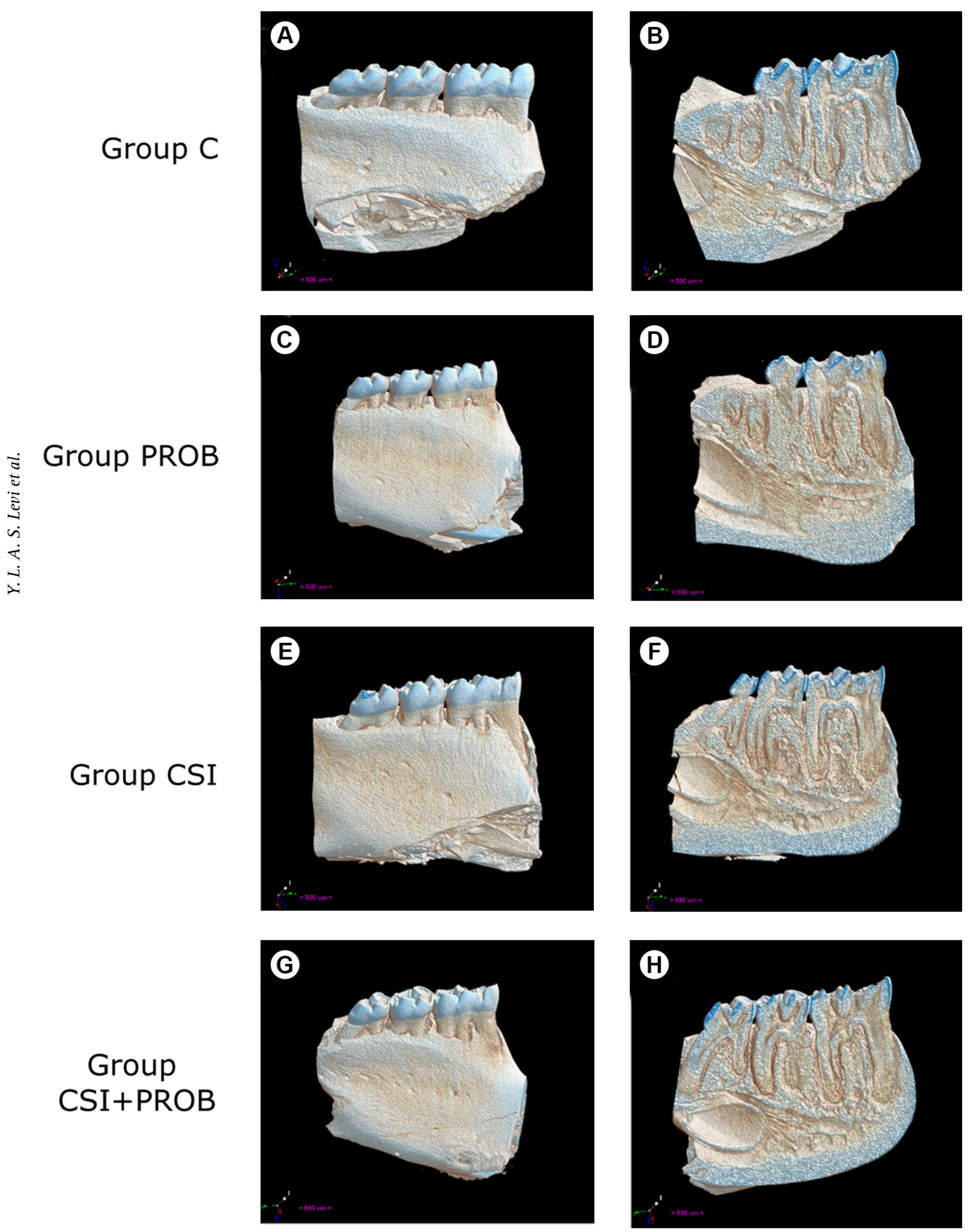

Figure 3. Three-dimensional rendered reconstructions of the microtomographic sections of groups C (A, B), PROB (C, D), CSI (E, F) and CSI+PROB (G, H). Buccal view (A, C, E, G). Internal surface view, sagittal section (B, D, F, H). Pixel size $=7.96 \mu \mathrm{m}$ 
human smokers, especially taking into account the large amount of daily nicotine ingested by them.

Probiotic was incorporated to feed and no significant differences were observed for feed intake among groups in anyone of the experimental periods, denoting that this was an effective route of administration. Regarding body weight gain, from month 3 to the end of the experiment, the groups submitted to CSI presented lower values when compared with groups $\mathrm{C}$ and $\mathrm{PROB}$, even considering that all groups consumed similar amounts of feed. A longitudinal study showed that the changes in weight caused by smoking are possibly mediated by systemic changes (22). Substantial evidence from experimental studies indicates that smoking has an appetitive-suppressive effect (23). In addition, other evidence shows that nicotine modifies the metabolic rate and energy expenditure including increased adipose tissue metabolism (via increased activity in lipoprotein lipase) (24). The PROB group presented greater weight at 4 and 6 months, when compared to the other groups. The weight and the intestinal microbiota composition are strongly connected, and the increase in weight after consumption of probiotics can be explained by the harvest energy from the diet performed by probiotic bacteria (25). However, these effects can vary according to the strain, some strains were related to weight gain, whereas others strains were associated with weight reduction (25).

For bone density, the micro-CT analyses showed a decrease in BMD on groups exposed to CSI. Corroborating these findings of this study, César-Neto et al. (1), using a similar methodology, described that CSI perform a negative effect over alveolar bone of rats, since the animals continuously exposed to CSI presented a decrease in mineralized tissue of the furcation area, when compared to the control group. Ribeiro et al. (26) also showed that when CSI is associated to experimental periodontitis induction a greater $A B L$ and a decrease in BMD of the furcation area occurs, when rats exposed or not to CSI are compared. In a recent study, Pompe et al. (6) evaluated computed tomography of current and former smokers and reported that current smokers show a fast decrease on $B M D$, inferring that smokers should be treated as high risk individuals for osteoporosis development and premature bone fractures. The authors also highlighted the importance of stop smoking in order to decrease the damage caused to bone tissue (6).

On the other hand, groups PROB and CSI+PROB showed a tendency of a greater BMD then groups $C$ and CSI, respectively, suggesting that probiotic administration may promote a protective effect on periodontal tissues. Corroborating with the results found in this study a study conducted by Parvaneh et al. (27) in ovariectomized rats demonstrated that probiotic administration increases the
BMD due to an increase in serum osteoclacin, osteoblasts and bone formation parameters. Besides, probiotics have the capacity to increase que amount of osteoprotegerin and decrease RANKL expression, preserve bone integrity, as it was verified by Oliveira et al. (11), when evaluating the effects of topic probiotic administration on experimental periodontitis.

Effects of probiotic bacteria on bone tissues involves many bacterial components and affect different pathways within the host (7). Probiotic bacterias may synthesize vitamins and enzymes that are required for matrix formation and bone growth, such as vitamins D, K, C and folate. In addition, bacteria of the strain Bifidobacterium produce short-chain fatty acids that can decrease the intestinal tract $\mathrm{pH}$, consequently increasing the absorption of minerals (7). The intestinal pro- inflammatory cytokine expression too have an important role on bone health (28). According to the results found in the present study, it can be inferred that exposure to cigarette smoke decreases $B M D$, and the administration of probiotic bacteria may increase BMD in animals exposed to cigarette smoke. This was a preclinical study which showed that probiotics can be considered an important ally in preventing the onset of bone diseases, such as osteoporosis, especially in smokers due to their effectiveness in increasing BMD.

The present study shows the local effect of probiotic administrations, however, one limitation is the absence of immunohistochemical analysis in order to evaluate the immunolocalization of the osteoclasts and mononuclear cells involved in the bone resorption process, the osteoclastogenic regulation pattern and the osteoclastic activation, to better understand the mechanism of action of probiotic bacteria in the bone tissue. Further research is needed to confirm the effects of isolated probiotic strains and associations between different strains, as well as different dosages and time of administration, involving bone tissue to elucidate the mechanism of action responsible for increased BMD.

It can be concluded that administration of probiotics promoted an increase in BMD and, consequently, a protective effect on the mandibular bone structures in rats exposed to inhalation of cigarette smoke.

\section{Resumo}

0 tabagismo é um dos principais fatores de risco para a doença periodontal, aumentando sua prevalência e gravidade. Os probióticos surgiram como uma alternativa para a prevenção e tratamento de muitas doenças, uma vez que podem modular a resposta imune do hospedeiro e promover a modificação do microbioma. Dessa forma, o objetivo do presente estudo foi avaliar os efeitos da administração de probiótico sobre os tecidos periodontais em ratos expostos à inalação de fumaça de cigarro (CSI). Quarenta ratos foram divididos nos seguintes grupos $(n=10)$ : grupo C (controle, sem CSI e probiótico); grupo PROB (controle+probiótico); grupo CSI (CSI) e grupo CSI+PROB (CSI+probiótico). Os grupos PROB e 
CSI+PROB receberam $2 \mathrm{~g}$ de uma associação de microrganismos probióticos incorporados à ração durante 6 meses. Os grupos CSI e CSI + PROB foram expostos à CSI por 60 minutos diários. Após seis meses, todos os animais foram eutanasiados e as hemi mandibulas coletadas e processadas para análises de microtomografia computadorizada. Em relação ao peso corporal dos animais, o consumo de ração foi semelhante entre os grupos, porém, após o segundo mês os grupos $\mathrm{C}$ e PROB apresentaram maior ganho de peso quando comparados aos grupos CSI e CSI+PROB $(p<0,05)$. 0 grupo $\mathrm{CSI}$ apresentou redução na densidade mineral óssea (DMO), enquanto que o grupo PROB apresentou os maiores valores $(p=0,01)$. Pode-se concluir que a administração de probióticos promoveu aumento da DMO e, consequentemente, efeito protetor sobre as estruturas ósseas mandibulares em ratos expostos à inalação de fumaça de cigarro.

\section{Acknowledgements}

This study was supported by the Scholarships for Scientific Initiation Program (PROBIC) of UNOESTE (Grant 2600). YLASL received a scholarship from the State of São Paulo Research Foundation (FAPESP) (2015/22837$5)$ and RNP received a scholarship from the Scholarships for Scientific Initiation Program (PROBIC) of UNOESTE (2600). The authors would like to thank Adriana Luisa Gonçalves de Almeida, technician of the Multi-user laboratory for three- dimensional images Analysis of Biological Tissues and Biomaterials of FORP-USP, for their technical assistance. The authors report no conflicts of interest related to this study.

\section{References}

1. César-Neto JB, Benatti BB, Sallum EA, Casati MZ, Nociti FH. The influence of cigarette smoke inhalation and its cessation on the toothsupporting alveolar bone: A histometric study in rats. J Periodontal Res 2006;41:118-123.

2. Bosco AF, Bonfante $S$, de Almeida JM, Luize DS, Nagata MJH, Garcia VG. A histologic and histometric assessment of the influence of nicotine on alveolar bone loss in rats. J Periodontol 2007;78:527-532.

3. Rosa GM, Lucas GQ, Lucas ON. Cigarette Smoking and Alveolar Bone Digitized Radiographs 2008;79:232-244.

4. Penoni DC, Leão ATT, Fernandes TM, Torres SR. Possible links between osteoporosis and periodontal disease. Rev Bras Reumatol Engl Ed 2017;57:270-273.

5. Tak I-H, Shin M-H, Kweon S-S, Nam H-S, Cauley JA, Kim O-J, et al. The association between periodontal disease, tooth loss and bone mineral density in a Korean population. J Clin Periodontol 2014;41:1139-1144.

6. Pompe E, Bartstra J, Verhaar HJ, Koning HJ De, Aalst CM Van Der, Oudkerk $\mathrm{M}$, et al. Bone density loss on computed tomography at 3-year follow-up in current compared to former male smokers. Eur J Radiol 2017;89:177-181.

7. Collins FL, Rios-arce ND, Schepper JD, Parameswaran N, Mccabe LR. The Potential of Probiotics as a Therapy for Osteoporosis. Bugs as Drugs 2017;5:213-233.

8. Camila A, Pazzini A, Jos L, Cristina C, Macari S, Silva L. Probiotic consumption decreases the number of osteoclasts during orthodontic movement in mice. Arch Oral Biol 2017;79:30-34.

9. Iqbal J, Yuen $T$, Sun $L$, Zaidi M. From the gut to the strut : where inflammation reigns, bone abstains 2016;126:2045-2048.

10. Jones RM, Mulle JG, Pacifici R. Osteomicrobiology: The influence of gut microbiota on bone in health and disease. Bone 2017;115:59-67.

11. Oliveira LFF, Salvador SL, Silva PHF, Furlaneto FAC, Figueiredo L, Casarin
$\mathrm{R}$, et al. Benefits of Bifidobacterium Animalis Subsp Lactis Probiotic in Experimental Periodontitis. J Periodontol 2017;88:197-208.

12. Muñoz Salas K, Alarcón Palacios M. Efecto de los Probióticos en las Condiciones Periodontales. Rev clínica periodoncia, Implantol y Rehabil oral 2010;3:136-139.

13. Teughels W, Durukan A, Ozcelik O, Pauwels M, Quirynen M, Haytac MC. Clinical and microbiological effects of Lactobacillus reuteri probiotics in the treatment of chronic periodontitis: A randomized placebocontrolled study. J Clin Periodontol 2013;40:1025-1035.

14. Stamatova I, Meurman JH. Probiotics and periodontal disease. Periodontol 2000 2009;51:141-151.

15. Villa CR, Ward WE, Comelli EM. Gut Microbiota-bone Axis. Crit Rev Food Sci Nutr 2017; 24;57:1664-1672.

16. Messora MR, Pereira $\amalg$, Foureaux R, Oliveira LFF, Sordi CG, Alves AJN, et al. Favourable effects of Bacillus subtilis and Bacillus licheniformis on experimental periodontitis in rats. Arch Oral Biol 2016;66:108-119.

17. Camargo RCT, Costalonga RR, Louzada MJQ, Fernandes RA, Camargo Filho JCS, Urban JB. The influence of passive tobacco exposure and physical exercise on bone tissue of young rats. Acta Ortopédica Bras 2017;25:77-80.

18. Cendon SP, Battlehner C, Lorenzi Filho G, Dohlnikoff $M$, Pereira PM, Conceição GM, et al. Pulmonary emphysema induced by passive smoking: an experimental study in rats. Braz J Med Biol Res 1997;30:1241-1247.

19. R Core Team. R: A language and environment for statistical computing. Vienna, Austria: R Foundation for Statistical Computing; 2016.

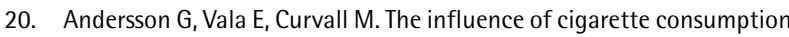
and smoking machine yields of tar and nicotine on the nicotine uptake and oral mucosal lesions in smokers. J Oral Pathol Med 1997;26:117124.

21. Blackford AL, Yang G, Hernandez-avila M, Przewozniak K, Zatonski W, Figueiredo V, et al. Cotinine Concentration in Smokers from Different Countries: Relationship with Amount Smoked and Cigarette Type. Cancer Epidemiol Biomarkers Prev 2006;15:1799-1805.

22. Munafò MR, Tilling $K$, Ben-Shlomo Y. Smoking status and body mass index: A longitudinal study. Nicotine Tob Res 2009;11:765-771.

23. Young-Hwan Jo, David A. Talmage and LWR. NIH Public Access. J Neurobiol 2012;53:618-632.

24. Ferrara CM, Kumar M, Nicklas B, McCrone $S$, Goldberg a P. Weight gain and adipose tissue metabolism after smoking cessation in women. Int J Obes Relat Metab Disord 2001;25:1322-1326.

25. Angelakis $\mathrm{E}$. Weight gain by gut microbiota manipulation in productive animals. Microb Pathog 2017;106:162-170.

26. Ribeiro F V, Pino DS, Franck FC, Benatti BB, Tenenbaum H, Davies $\mathrm{JE}$, et al. Resveratrol Inhibits Periodontitis-Related Bone Loss in Rats Subjected to Cigarette Smoke Inhalation. J Periodontol 2017;88:788798.

27. Parvaneh K, Ebrahimi M, Sabran MR, Karimi G, Hwei ANM, AbdulMajeed $S$, et al. Probiotics (Bifidobacterium longum) increase bone mass density and upregulate Sparc and Bmp-2 genes in rats with bone loss resulting from ovariectomy. Biomed Res Int 2015;2015:897639.

28. Mccabe LR, Irwin R, Schaefer L, Britton RA. Probiotic use decreases intestinal inflammation and increases bone density in healthy male but not female mice. J Cell Physiol 2013;228:1793-1798.

Received April 3, 2019

Accepted July 22, 2019 